\section{CLÍO: ¿LA HISTORIA EN OCCIDENTE SE CONVIRTIÓ EN UN LUGAR DE MEMORIA?}

\author{
CLÍO: DID THE STORY IN THE WEST \\ BECOME A PLACE OF MEMORY?
}

\section{FRANÇOIS HARTOG •}

École des Hautes Études en Sciences Sociales (EHESS)

de París (Francia).

Email: francois.hartog@ehess.fr

\section{Resumen}

El trabajo explora la diferente fortuna de la historia como disciplina a través del tiempo y sus cambiantes relaciones con la memoria. Del pasaje de la historia como magistra vitae a la historia como una nueva religión con aspiraciones científicas. En otros términos, del pasaje del régimen antiguo de historicidad, en que el presente era esclarecido por el pasado, al régimen moderno, en que el presente era esclarecido por el futuro. Sin embargo, el largo dominio de Clío fue oscurecido por otra musa, su madre: «Mnemosine». La memoria reclamó sus derechos, luego de los cataclismos del siglo XX y se enseñorea ahora sobre la historia en la vieja Europa. Sin embargo, en el contexto de un mundo ahora plural, de un pasaje de una idea singular a una idea plural de "civilización» una nueva concepción y un nuevo papel esperan para la historia. El mismo, sin embargo, difícilmente será diseñado en los talleres de Europa.

\section{Registro bibliográfico}

HARTOG, FRANÇOIS «Clío: ¿la Historia en Occidente se convirtió en un lugar de memoria?», en: ESTUDIOS SOCIALES, revista universitaria semestral, año XXX, $n^{\circ} 58$, Santa Fe, Argentina, Universidad Nacional del Litoral, enero-junio, 2020, pp. 103-117.

\section{Abstract}

The work explores the changing relationship between history and memory through the time. It studies the change from a vision of history as magistra vitae to the vision of history as a new religion, with scientific aspirations. However, the long dominion of Clio was obscured by the rise of another muse, his mother: «mnemosine». Memory claimed its rights after the cataclysms of the 20th century and now dominates over history in old Europe. However, in the context of a now plural world, with a change from a singular idea to a plural idea of «civilization», a new conception and a new role await history. This new role, however, will hardly be designed in Europe's factories.

\section{Descriptores - Describers}

historia / memoria / progreso / civilizaciones History / Memory / Progress / Civilizations

Recibido: 11/10/2019 Aprobado: 05/02/2020 
"C’est moi qui fus la belle Clío si adulée» ${ }^{1}$

(CHARLES PÉGUY).

\section{INTRODUCCIÓN}

¿Es la historia un lugar de memoria europea? He aquí una pregunta muy iconoclasta que en la década de 1970 habría sorprendido todavía (e incluso impactado) a los historiadores. Más aún, ellos no la habrían sencillamente comprendido. Porque se aceptaba que por un lado estaba la memoria, y del otro la historia —su dominio-, que comenzaba allí mismo donde la memoria se detenía. Fueron los cambios acontecidos luego, marcados fuertemente por el incremento de la memoria en Europa y fuera de ella, los que condujeron a interrogar a la Historia, al mismo tiempo como disciplina y como creencia mayor del mundo moderno, es decir, de un mundo que hoy ya no es el nuestro. Desde ese momento, ¿puede la Historia que iba de la mano con este mundo moderno y que incluso ayudó a decirlo y a darle un sentido (el sentido de la Historia, justamente) ser todavía la nuestra? (HARTOG, 2OI3).

No es cuestión de trazar aquí el largo camino del nombre «Historia» en Europa desde que Heródoto lo lanzara al ruedo durante el siglo v antes de nuestra era. Si el nombre ha atravesado veinticinco siglos sin ser jamás abandonado, diversos han sido en cambio sus empleos y numerosas las maneras de comprenderla. Porque, retomándolo, cada época lo ha plegado a sus propios propósitos, manteniendo para sí siempre una parte, variable y siempre revisable, de aquellas maneras en las que ha sido usado. Estaba ahí, a la vez familiar y práctica, habiendo adquirido rápidamente una gran visibilidad, y cada vez que se renovaba permitía ordenar lo que había sucedido y lo que sucedía, y ofrecía nuevas perspectivas sobre el mundo y su pasado. ¿De qué se trataba sino de comprender más para actuar mejor en el presente, su presente? En cada uno de sus presentes sucesivos.

Desde la Antigüedad, Clío fue reconocida como la Musa de la Historia, pues aquellos a quienes ella cantaba adquirían la bella gloria (Kleos). Lo que nos recuerda que en Grecia la primera historia surgió de la epopeya. Antes de Heródoto, estuvo Homero. Y durante mucho tiempo, la historia celebró las grandes hazañas, la vida de los príncipes y los grandes hombres, con la intención de ofrecer ejemplos a imitar (y a veces para no hacerlo). Pero hoy, Clío parece haber sido suplantada en

1] «Soy yo quien ha hecho a la bella Clío tan adulada». 
nuestras sociedades por Mnemosine, Memoria, conocida — a partir de Hesíodocomo la madre de las musas. Digamos que, por una suerte de filiación inversa, la madre tomó el lugar de la hija. Ya no es más la historia la que juzga y calibra a la memoria, sino que es en cambio la memoria la que volviéndose hacia la historia la cuestiona, e incluso la rechaza; $y$, en todo caso, resulta hoy difícil comprender lo que ella pudo representar entre fines del siglo Xvin y hasta el siglo xx, para un mundo en el cual ella aspiraba a devenir la nueva religión. Este período correspondió a la instauración del mundo moderno: naciones e imperios coloniales caminaron mano a mano. Pero, dos guerras mundiales más tarde, una Europa desangrada y en ruinas abandona sus imperios y se entrega en cuerpo y alma a su propia reconstrucción. Comienza así otra era, que será aquella de la guerra fría, de la carrera del progreso y de los armamentos entre el este y el oeste, y que duró hasta la caída del muro de Berlín en 1989, seguida del derrumbe del imperio soviético.

Pero esta historia es bien conocida, y no es acerca de ella de lo que se trata aquí. Visto en retrospectiva, este siglo y medio aparece como una época de historia universal, particularmente activa, agitada, violenta, que revolucionó el mundo conjugando descubrimientos de la ciencias, proezas tecnológicas y destrucciones varias, avances sociales y explotaciones feroces, regímenes democráticos y dictaduras brutales, muertes por millones, crímenes de masa y genocidios: todo en una escala increíble y a un ritmo nunca visto. De entre todas las condiciones que hicieron posible este trayecto singular, que hizo algo más que agregar un nuevo capítulo al viejo esquema de la sucesión de los imperios (tal como se leyera durante largo tiempo en el Libro de Daniel, reconociendo allí el trauma de una historia providencialista), la Historia — quiero decir la concepción de la historia o, mejor aún, el concepto moderno de Historia—, jugó un rol: ¿̨u rol? Y si esto es así, ¿̨cuál fue ese rol y y cuáles las vías de su despliegue? Para responder a estas preguntas partiremos de una proposición general, que intentaremos verificar. En base a nuestra experiencia del tiempo, el concepto de historia no puede sustraerse de una modificación equivalente a aquella sufrida por nuestro vínculo con el tiempo. Porque, desde la elaboración de los primeros calendarios, los grupos humanos siempre han hecho del tiempo un objeto social y un desafío religioso, político y económico. Y es que la instauración de un tiempo propiamente «histórico» coincide con lo que nosotros llamamos «tiempo moderno».

Partimos de la definición de la Historia brindada por Pierre Larousse en los años I870, en un momento donde ella era reconocida como una potencia establecida: 
«El movimiento histórico, inaugurado en el siglo XVII por Bossuet, continuado en el xviII por Vico, Herder, Condorcet, y desarrollado por tantos espíritus notables de nuestro siglo XIX, no puede sino acentuarse con incluso más vigor en un futuro próximo. Hoy la historia devino, para decirlo de algún modo, una religión universal. (...) Ella está destinada a volverse, en medio de la civilización moderna, eso que la teología fue en la Edad Media y en la Antigüedad, la reina y moderadora de las conciencias» (LAROUSSE, I866/I877, XII: 30I).

¿Qué es lo que hizo falta, nos preguntamos, para que haya sido posible tal profesión de fe en la historia y en su futuro? Recorrer un largo camino, cuyas principales etapas tuvieron por nombre: el reconocimiento de que son los hombres los que hacen la historia, el pasaje a través de una concepción de perfectibilidad del progreso, la salida del yugo de seis mil años de cronología bíblica y la apertura hacia un futuro indefinido. El tiempo, para hablar como Ernest Renan, aparece desde ahora como «el factor universal, el gran coeficiente del eterno devenir. Aunque todas las ciencias, escalonadas por su propio objeto en un momento de su duración, devinieran históricas y aunque la historia de las sociedades humanas se revelara como la más joven de las ciencias» (RENAN, 1974, I: 634). Se pasó de una historia maestra de vida y sujeto de la retórica a la Historia maestra del universo, escribana del devenir y aspirante a tornarse una ciencia. Se salía de eso que di en llamar «el antiguo régimen de historicidad» para entrar en el régimen moderno de historicidad, que se caracteriza por la predominancia de la categoría de futuro y por una separación cada vez mayor entre el campo de la experiencia y el horizonte de la espera, para retomar las categorías desplegadas por el historiador alemán Reinhart Koselleck (HARTOG, 20I2; KOSELleCK, 20I6: 307-329). El futuro es el telos: el objetivo. De él proviene la luz que esclarece el pasado. El tiempo ya no es más un simple principio de clasificación sino el actor, el operador de una historia-proceso, que es otro nombre - o el nombre verdadero- del progreso. Esta historia que los hombres realizan es vivida como acelerada. En este mundo devenido histórico no se puede más que creer en la Historia: esta creencia puede ser difusa, reflexiva (teorizada por los filósofos de la historia, como Hegel y Marx), o cuestionada, pero en todo caso se comparte cada vez más. Es Alexis de Tocqueville quien, en I840, brinda la formulación más clara: «Cuando el pasado no esclarece más el futuro, el espíritu camina en las tinieblas» (TOCQUeville, I98I, II: 399). Con estas palabras, justamente, pone fin al antiguo régimen de historicidad (donde la 
luz provenía del pasado) y da al mismo tiempo la fórmula del régimen moderno, es decir la clave de inteligibilidad del mundo después de 1789, momento a partir del cual es el futuro el que esclarece al pasado y marca el camino de la acción. Es desde el futuro —en este caso y según él—, desde Estados Unidos, que conviene mirar hacia Francia y Europa para descubrir allá la marcha irresistible hacia la igualdad de condiciones.

De este modo el espíritu no avanzará, al menos, en las tinieblas. En tiempos nuevos, se necesita una historia nueva. Porque la que se liga al antiguo régimen de historicidad ya no resulta más operativa: no esclarece más nada. En el antiguo régimen de historicidad (antes de 1789, para tomar esta fecha simbólica), los actores poseían sin duda su presente, vivían en este presente, intentando comprenderlo y dominarlo. Pero para identificarse y dar sentido a su experiencia histórica comenzaron a mirar de costado hacia el pasado, con la idea de que él era portador de inteligibilidad, de ejemplos, de lecciones. Mientras que en el régimen moderno es a la inversa: se mira hacia el futuro, es él quien esclarece el presente y permite explicar el pasado; es hacia él que hay que ir lo más rápido posible. Él orienta las experiencias históricas y la historia es ahora teleológica: el fin indica el camino ya recorrido y lo que queda aún por recorrer. Todas las historias nacionales e imperiales modernas fueron concebidas y escritas sobre este modelo: en Europa primero, y luego en el resto del mundo. Este se volvió el patrón sobre el cual se tallaron las diferentes historias y, al mismo tiempo, el criterio de entrada en la modernidad y una medida de las distancias que quedan por transitar. El «ya» queda del lado de Europa (el centro) y el «todavía no» vale a partir de entonces para el resto del mundo (la periferia).

El descubrimiento y la puesta en funcionamiento de la historia-proceso, regida por el progreso, correspondió a los tiempos felices, seguros de sí y vencedores, de las filosofías de la historia, de las historias universales o de la Civilización. Como bien lo señalaba François Guizot en su curso en la Sorbona de 1828, «la idea de progreso, de desarrollo, parece ser la idea fundamental contenida en la palabra civilización»; y ella conlleva al menos dos dimensiones: el desarrollo de la sociedad humana y el desarrollo del hombre mismo. En definitiva, «es la idea de un pueblo que camina, no para cambiar de lugar, sino para cambiar de estado». De este modo habría «una historia universal de la civilización por escribir» (GUIzot, I985: 62). Se tuvo que esperar hasta el siglo xx para comenzar a escribir Civilización en plural. Llevado por la aceleración, el tiempo moderno acarrea con él las nociones de anacronismo, de supervivencia, de vanguardia, de retraso; y, a partir de Charles Darwin, de 
evolución, que una vez aplicada a las sociedades humanas, con Herbert Spencer, advino en evolucionismo. El ferrocarril es rápidamente percibido como viniendo a inaugurar «una nueva era en la historia de la humanidad» y, en I837, el poeta Adalbert von Chamisso pretendía "tomar el tren acoplado en Zeitgeist (espíritu de los tiempos); yo no hubiera podido morir en paz si no hubiera echado una mirada, desde lo alto de este carro de triunfo, sobre el futuro que se desplegaba» (cit. en KOSELLECK, 2000: 176). No se podría expresar de manera más ilustrada y optimista el embarque en el régimen moderno de historicidad. Para Marx, adepto también al ferrocarril, las revoluciones serían interpeladas a convertirse, algunas décadas más tarde, en las «locomotoras de la Historia».

\section{FUERA DE EUROPA/ MÁS ALLÁ DE EUROPA}

Fuera de Europa, el tiempo moderno hace pasar al salvaje del estatuto de menor de edad (que poseía desde el siglo Xvi en el discurso de los misioneros y de los colonos) al de "primitivo». No completamente fuera del tiempo (pero muy lejano), este se encuentra en todo caso situado por fuera de la Historia, y estrictamente hablando no posee historia. No tiene al menos historia verdadera; no según el sentido nuevo brindado por el concepto moderno de Historia, que se instala como administradora del mundo y se erige en «la nueva teología»: la universal Clío. Así, este indígena regresa hacia sus colonizadores para hacerse ingresar en la Historia, haciéndolos estos últimos subir (por la fuerza si fuera preciso, pero también por su bien) en el tren de la Historia.

Resulta llamativo el cambio de la relación — mediado un siglo—, entre JeanJacques Rousseau y los fundadores de la etnología. En su Discurso sobre el origen de la desigualdad (I775), Rousseau invitaba al filósofo al viaje:

«Toda la tierra se halla cubierta de naciones de las cuales solo conocemos sus nombres. Y así pretendemos juzgar el género humano. Supongamos un Montaigne, un Buffon, un Diderot, viajando, observando y escribiendo. (...) Supongamos que terminan luego escribiendo la historia natural, moral y política de lo que hubieran visto: contemplaríamos surgir un nuevo mundo de sus plumas, aprendiendo así a conocer el nuestro» (ROUSSEAU, I964, III: I3-I4).

Aquí el filósofo y el salvaje están en el mismo plano: en el mismo tiempo. 
Algunas décadas más tarde, con la Société des Observateurs de l'Homme, fundada en I799, el viaje filosófico se naturaliza y se temporaliza: se remonta hasta los orígenes de la humanidad. Los pueblos salvajes «nos señalan la historia de nuestros propios ancestros» y su observación nos permite componer «una escala exacta de los diversos vaivenes de la civilización» (COPANS Y JAMIN, 1994: 76). Se está cómodo con la civilización en singular, y la toda medición tiene lugar a partir del centro. Mientras uno más se aleja de allí, más se desciende en los grados de la escala civilizatoria.

Pero advenido el evolucionismo la temporalización se instala ya totalmente, y el salvaje se transforma entonces en primitivo. Éste es entonces menos visto como nuestro ancestro que como el último contemporáneo del mamut lanudo. Es cierto, el primitivo está en el tiempo (y no fuera de él como el hombre natural de Rousseau), pero en un tiempo demasiado remoto para nosotros. Es un anacronismo viviente o un sedimento. Reencontrar las tribus salvajes actuales es equiparable a visitar los «monumentos del pasado», destaca Lewis Morgan (MORGAN, I97I: 45). Para Edward Tylor, otro de los padres fundadores de la etnología, los últimos tasmanos (los Palawa) son — literalmente— los hombres del Paleolítico: «el hombre del Paleolítico deja de ser una inferencia filosófica para volverse una realidad tangible» (cit. en STOCKING JR., 1987: 283). Mientras que, tras los primeros encuentros con ellos al comienzo del siglo de XIX, se aparecen frente a sus descubridores como los representantes del feliz estado de naturaleza. Los infantes de antes se vuelven de repente muy viejos (lo cual no impide, por otra parte, que se continúe tratándolos como a niños). La mención del hombre del Paleolítico hace eco directo con el desarrollo, durante esos mismos años, de la prehistoria. Se ha pasado del hombre antediluviano de Bocher de Perthes al hombre prehistórico. Los canteros de excavación se multiplican. Apoyándose sobre estos descubrimientos recientes, los primeros etnólogos fijan entonces un marco general para su quehacer. Ellos delinean de este modo un tiempo etnológico y determinan los estadios en el desarrollo de la humanidad, con la clásica tripartición en salvajes, bárbaros y civilizados. En su Ancient Society, publicada en 1877, Lewis Morgan hace un poco más sofisticado el corte: el estadio salvaje se divide en inferior, medio y superior, siguiendo el modelo arqueológico. Lo mismo sucede con la barbarie. En cuanto al estado civilizado éste se divide, sin sorpresa, en antiguo y moderno, reuniendo la pareja bien establecida de Antiguos y Modernos.

De esta forma el régimen moderno de historicidad presenta dos vertientes: por un lado, la del progreso y la aceleración (en Europa, el centro de entonces); por otro, la de la evolución (en otros lugares, en la periferia). En un polo se encuentra 
el hombre moderno, siempre más habitado por el futuro; en el otro, el primitivo, que permanece en un tiempo estancado o en un presente permanente. Entre ambos, todas las combinaciones o los regímenes temporales intermedios son posibles. ¡Nunca faltarán posibles clasificaciones! La colonización supo cómo emplearlas ventajosamente. Cierto, la evolución o el devenir valen para el universo entero, pero solo Europa (y sobre todo Alemania, Inglaterra y Francia) supo extraer del devenir este tiempo inaudito que resulta ser el tiempo moderno, que transmuta (para decirlo de algún modo), tal como los alquimistas, el tiempo antiguo, el del antiguo régimen de historicidad — formado él mismo por un compuesto de aleaciones-en un tiempo nuevo. Esta operación, por cierto laboriosa, que se extendió por varios siglos, no estaba sin embargo inscrita por toda la eternidad en el destino de Europa; bien hubiera podido tornarse de otra manera. Todo lo que se puede decir al respecto es que un conjunto de condiciones lo volvieron posible. Ya he enunciado algunas. Sobre este terreno de alguna manera preparado, la Historia, llevada por este tiempo futurista, estaba lista para tejer los grandes relatos, incluso aquellos con los cuales las naciones europeas han consolidado, por una parte, su elección — justificando su dominación-, y por otra agudizado su rivalidad y alimentado sus antagonismos. Al menos hasta la ceguera completa de ambas partes, durante el curso de la Gran Guerra.

Dos alegorías nos permiten ver este momento de la Historia que se puede calificar, en el sentido que venimos analizando, de europea. La primera muestra el vuelo de la Historia o la puesta en marcha del régimen moderno de historicidad; la segunda, su caída: una Historia clavada al suelo y un tiempo detenido. La primera es un cuadro dedicado a la gloria de Napoleón, ejecutado por Alexandre Véron-Bellecourt, un pintor académico, que presentó muchas escenas de la gesta imperial. El cuadro lleva por título: «Clío muestra a las naciones los hechos memorables de su reino»; fue presentado en el salón de $1806^{2}$. Se ve allí, en efecto, una Clío, vestida a la antigua, señalando con el dedo lo que viene de inscribir sobre una gran estela, a saber: las grandes hazañas de Napoleón, a un grupo de hombres en trajes más o menos exóticos, indígenas con sus plumas, turcos, orientales e incluso chinos, que se reúnen allí como alumnos estudiosos delante de un pizarrón negro. En un segundo plano, el Louvre. Napoleón está presente, con la forma de su busto de emperador romano, con la inscripción veni, vidi, vici, que lo designa como al nuevo César. Al pie de

2] Este cuadro, de buenas dimensiones (3,380 $\mathrm{m} \times 2,750 \mathrm{~m}$ ), se conserva en el Louvre. 
Clío aparecen varios rollos (los trabajos anteriores de Clío) y se pueden descifrar los nombres de Heródoto, de Tucídides y de Jenofonte. Propiamente clásica, la puesta en escena obedece todavía a los cánones de la historia magistra vitae: un ejemplar del gran hombre a la manera de Plutarco y una Clío diseminando su gloria.

Pero hay algo más, otorgado por el mismo movimiento del cuadro: Napoleón no es solamente César, es también una encarnación de la propia Historia: es esta fuerza que se abre paso y cuyos efectos se hacen sentir hasta en los confines del mundo. Allí donde Hegel reconoció al Espíritu del mundo avanzar mientras atravesaba Jena a caballo. En sus Memorias de ultratumba, Chateaubriand decía de él que, durante dieciséis años, había sido el Destino, y un Destino que nunca descansa, continuamente en movimiento para remodelar Europa. Era «el conquistador que franqueaba la tierra» (CHATEAUBRIAND, 2003/2004, I: I2I9 y II3I). En él convergían las manifestaciones de los trazos de la Historia moderna: su dominio sobre el destino de los países y de los hombres y su velocidad de ejecución: ella no permanece nunca en reposo. Napoleón surgió cuando se lo esperaba en otro lugar o más tarde.

Bajo el efecto de un tiempo, convertido en actor y en proceso, él establece la sincronización del mundo: hasta la China. Es lo que traduce la composición del cuadro. El régimen moderno de historicidad galopa. Para escribir, la Historia pasa del establecimiento de sincronismos (indispensables para establecer el antes y el después) a la sincronización que organiza, según una escala del tiempo, el «antes que» y el «más tarde que», el avance y el retroceso (en el cual el exotismo de las costumbres es una huella): el «ya» y el «todavía no». El conquistador es también el gran sincronizador: cosmokrator y chronocrator, señor del mundo y señor del tiempo. Sus rápidos galopes a través de Europa, con sus trenes de artillería y el Código Civil en su equipaje, expresan también un choque de temporalidades. Con esta alegoría se le sitúa entre la historia magistra y la nueva historia. El vuelo del águila representa así también el vuelo de la Historia.

$\mathrm{Al}$ otro extremo del arco, una segunda alegoría traduce la caída de la Historia. Se trata de una escultura, creada por Anselm Kiefer en $1989^{3}$. Titulada Ángel de la Historia o también Amapolas y memoria, hace referencia directa al Ángel de la Historia de Walter Benjamin, quien, él mismo, meditaba sobe el cuadro que Paul Klee había titulado Angelus novus. Aquí, el ángel no aparece más que bajo la forma

3] Kiefer ofreció este Ángel al Museo de Jérusalem en 1990. Cfr. ARASE (2001: 216-217). 
de un pesado bombardero de plomo. Kiefer se había procurado una gran cantidad de plomo proveniente del techo de la catedral de Colonia. De gran tamaño, el avión — cabina y alas estrujadas - , parece sobre todo exhumado de una excavación arqueológica antes que listo para salir al vuelo. La Historia de la que él era el mensajero, aquella de los muertos y las destrucciones, tuvo ya lugar. Sobre las alas, a izquierda y derecha, hay dispuestos espesos libros, de plomo también, de donde emergen las flores de amapola. De ahí proviene el otro título de la obra, que renvía a la colección de Paul Celan, Amapolas y memoria, publicada en I952, en la que se trata, a propósito de la Shoah, de la memoria y del olvido. La amapola, indicó Celan, «implica el olvido». Su flor, que al mismo tiempo conlleva el olvido e impide la memoria, provoca, en definitiva, un olvido imposible de olvidar.

Recordemos aquí solo la alegoría de una historia congelada: el Ángel ya no reanudará su vuelo, ni el avión tampoco. El tiempo se detiene y flota un silencio mortal. El espectador se enfrenta a un pasado que no pasa o a un presente sin fecha, con el que solo se puede establecer una relación donde la memoria y el olvido se mezclan o, más bien, chocan y cuyo silencio, con sus múltiples valencias, de hecho, ha sido la mayor expresión durante años. Un orgulloso vector de avance de la técnica, siguiendo el ferrocarril de la década de 1830, el avión, clavado en el suelo, es en sí mismo un testimonio en ruinas. Ahora pertenece a las ruinas que creó. ¿Puede el tiempo moderno, el del régimen moderno de historicidad, volver a encarrilarse y cuáles podrían ser los cantos de gloria de Clio?

Esbozada en 1945 pero concretada a finales de 1980, la obra de Kiefer se desprende de la Memoria: pretende hacer memoria de la catástrofe y conjurar el olvido. En sintonía con el ascenso de la Memoria, refuerza la visibilidad. Dos memoriales (de entre otros posibles) testimonian esta conjuntura donde la Memoria se volvió el punto de vista desde el cual mirar la Historia. Se está, de hecho, en eso que el psicoanálisis llamó l'apres-coup. Estos monumentos, por su concepción y por su arquitectura, son ya por sí mismos, testimonios. El primero es el Memorial a los judíos asesinados en Europa, inaugurado en el 2005, en Berlín. Situado sobre un terreno cercano al bunker de Hitler, es obra del arquitecto americano Peter Eisenmann. El visitante descubre un campo de 2700 lápidas de cemento gris, dispuestas de manera desigual, brindando la impresión de un cementerio abandonado y en ruinas. Sin otra indicación ni explicación, se está invitado a deambular entre las lápidas y a dejarse impresionar, a perturbarse por el lugar. A través de este laberinto sin palabras, la memoria pasa por el afecto. Si el visitante quiere 
la historia, debe ir al subsuelo, el «lugar de la información». Ahí, una exposición permanente invita a ver y a leer las diferentes huellas del exterminio. Este centro historiográfico no estaba previsto en el proyecto inicial, llegó posteriormente en auxilio de la memoria. El «lugar de la historia» está puesto al servicio del lugar de la memoria que pretende antes que nada ser el monumento.

Si remontamos hacia atrás el curso del tiempo, la Memoria se apoderó también de la guerra de 19I4, mientras desaparecían los últimos combatientes. Los habitantes del centenario fueron testigos de múltiples celebraciones. Así, el in de noviembre de 20I4, el presidente de la República Francesa inauguró un nuevo Memorial: «El anillo de la Memoria o Memorial Internacional de Notre-Dame de Lorette». Este lugar, próximo a Arrás, era ya el sitio de una «necrópolis nacional», inaugurada en 1925 y albergue de los restos pertenecientes a los soldados muertos durante los violentos combates que habían tenido lugar en la colina de Notre-Dame de Lorette, entre I9I4 y 1915. Formado por una gran elipse, el Memorial (obra del arquitecto Philippe Prost), presenta sobre la cara interna del anillo unas placas que muestran 580000 nombres de combatientes muertos entre I9I4 y I9I8. Perteneciendo a cuarenta nacionalidades, los nombres se siguen, sin ninguna distinción, por orden alfabético. Ingresando al interior del Anillo a través de una trinchera, el visitante penetra, para decirlo de algún modo, en la memoria del lugar; y, si lo desea, la historia puede decirle más sobre estos nombres, debidamente compilados en los registros oficiales de los diferentes Estados beligerantes. Pero nada más, nada más allá. El anillo se cierra sobre sí mismo. El equilibrio estable de la construcción (al menos su puesta en escena) indica quizá la fragilidad de la Memoria. Si el lugar ya no fuese visitado, si los nombres no fuesen leídos, entonces el olvido ganaría definitivamente la partida. Así, del cuadro de Véron-Bellecourt hasta el Anillo de la memoria, pasando por el Ángel de la Historia de Kiefer y el Memorial de Berlín, la marcha de la Historia se transformó en los caminos de la Memoria.

Tal es el movimiento general y el cambio que se produjo, conduciendo desde la puesta en marcha del régimen moderno de historicidad hasta su puesta en tela de juicio, de un futuro glorioso e imperioso a un futuro dudoso y amenazador. Del futurismo al presentismo, al menos en Europa. Ahora bien, desde hace ya mucho tiempo, al menos desde este «suicidio de Europa», diagnosticado por Paul Valeri desde 1919, Europa ya no es más el centro, y su Clío tiene plomo en las alas. Sostener que los historiadores no hayan hecho más que retomar el mantra de Larousse, con total ignorancia de lo que se había jugado y continuaba 
jugándose, sería totalmente falso; los cuestionamientos se expresaron y algunas reformulaciones fueron propuestas. De entre ellas, citamos la de los fundadores de los Annales, Marc Bloch y Lucien Febvre, quienes pretendieron volver a colocar la relación pasado-presente en el corazón del curso de la historia. Del lado de los antropólogos, Claude Lévi-Strauss rechazaba en Raza e Historia (1952) el evolucionismo y mostraba las civilizaciones menos como escalonadas en el tiempo que como talladas en el espacio. De ello se extraía la impresión de que el progreso estaba disminuyendo de «categoría universal» a la de solo un «modo particular de existencia propio a nuestra sociedad» (LÉVI-STRAUSS, I958: 368).

Pero mi propósito no es detenerme sobre estas críticas, porque nos queda aún intentar presentar a Clío, esta vez no desde interior de Europa, sino desde su exterior. Hasta este momento el punto de vista —interno, sobre todo— se situó sobre dos registros: Clío y el tiempo o el concepto modernos de Historia, y Clío vista desde la Memoria o la caída del régimen moderno de historicidad. Por supuesto, esta moderna Clío viajaba en el equipaje del colonizador, que buscó objetivarla y naturalizarla, presentándola como la dueña del mundo y la dueña del tiempo. En retrospectiva, el éxito de la conquista y de la dominación contribuyó a validar su pertinencia. Una vez dejado de lado, el esquema cristiano de una Historia de Salvación y de providencialista, y una vez puesto en marcha el tiempo moderno, el evolucionismo proporcionó un nuevo marco operativo; luego, el marxismo aportó la ciencia de la Historia, y, después de 1945, el desarrollo y la modernización se convirtieron en las consignas de las grandes organizaciones internacionales, como la ONU, y de la descolonización. Lo que se estaba produciendo entonces no era nada menos que una transferencia del régimen de historicidad: cada uno podía tener su vagón en el tren de la historia, e incluso su propia locomotora. Allí estaban la aceleración, la primacía del futuro, la nación y el nacionalismo, es decir la historia teleológica que conlleva todo esto. Tenían también curso las variantes, más o menos revolucionarias, que se hundían en el motor de la lucha de clases, uno de cuyos desafíos principales consistía en saber a quién le estaba asignado el rol del proletario en tanto sujeto histórico. La revolución china dio a este respecto un gran golpe. El marxismo podía ayudar a perseguir al colonizador, pero era al mismo tiempo la punta de lanza más avanzada del régimen moderno de historicidad. Con él era necesario hacer desaparecer al pasado, sus injusticias y sus supersticiones (religiosas), y estar listos para sacrificar a las generaciones presentes, desenmascarando a los contrarrevolucionarios para hacer avanzar el futuro lo antes posible. 
Una nota del historiador Dipesh Chakrabarty resulta muy esclarecedora. Comentando su inicio como historiador en Calcuta en el seno de este grupo luego devenido célebre, el de los Subaltern Studies (que en los años 1970 reunía a historiadores indios partidarios del marxismo), escribe que, para ellos, «Marx era un nombre bengalí de aquí» (CHAKRABARTY, 2009: 2I). Jamás, en efecto, se preguntaron nada relacionado sobre sus orígenes alemanes, sobre las categorías intelectuales que movilizaba ni sobre la historia de su formación en el seno del pensamiento europeo. En definitiva, la cuestión de la relación entre pensamiento y lugar no tenía cabida. Chakrabarty daba "por sentado, la pertinencia universal del pensamiento europeo» (CHAKRABARTY, 2009: 2I). No será sino hasta algunos años más tarde y desde Australia, donde él vivía en ese momento, que pudo emprender un trabajo reflexivo que lo condujo a Provincializar Europa, título de su libro que rápidamente se volvió una referencia ineludible de los estudios postcoloniales. Provincializar Europa es comprender en qué sentido Marx no es «un nombre bengalí de aquí». Es decir, medir cómo las categorías que él movilizaba tenían en efecto una historia propia y, sobre todo, ponerse en posición de percibir la distancia que operaba entre estas categorías y las realidades no-occidentales que se suponía debían aprehender. Esta vía de retorno crítico sobre la Historia europea es interesante, porque afronta la difícil cuestión de saber qué hacer en el momento actual. Pero hay otras opciones, más radicales, que han defendido y defienden aún la idea de un rechazo completo y definitivo. No ya provincializar, sino olvidar Europa.

El desplazamiento temporal entre el avión de Kiefer (que nos retrotrae a 1945) y la fecha de la escultura (1989) da la medida del tiempo que fue necesario, en Europa, para cobrar conciencia de que el régimen moderno de historicidad había fracasado ya en 1945. Incluso, si (y quizá sobre todo si) las décadas siguientes fueron las de una carrera desenfrenada hacia el progreso, hacia las armas y también hacia el olvido en el contexto del antagonismo entre el este y el oeste, marcado por la crisis de la guerra fría. Aquellos años, se podría pensar retrospectivamente, también hicieron eco. Ahora bien, 1989 marca la caída del muro de Berlín y el anuncio del fin del imperio soviético. Se puede reconocer allí el golpe final asestado al tiempo moderno y al concepto moderno de Historia. Porque la ideología que se había pretendido la más futurista (con las decenas de millones de muertos que dejaba detrás de ella) había gravemente fracasado. Si el astro había, de hecho, muerto desde ya hace bastante tiempo, su luz continuaba en cambio llegando hasta diferentes lugares de la tierra, y las escuelas históricas que lo reivindicaron continuaron y algunas 
continúan todavía. No obstante, los fracasos de la efervescencia revolucionaria de los años 1950-1960, la cual se pretendía portadora de una organización como la «Tricontinental», condujeron a los progresistas de aquí y de allá a apartarse de una modernidad que los había — una vez más — engañado. En el Medio Oriente, la revolución iraní de 1979 venía a abrir una nueva vía y permitía «la sustitución del discurso religioso de referencia por el discurso de izquierda» (INSEL Y KAWAKIBI, 2016: 69). Otro futuro, con tonalidades a veces apocalípticas, se perfilaba en el horizonte. El concepto moderno de Historia terminaba de perder su capacidad para otorgar un sentido, mientras que aquello que habíamos llamado fundamentalismos (y también algunos movimientos indigenistas) ganaban en potencia y visibilidad.

Y Clío, alguna vez «tan adulada», ¿en qué se convertía? ¿Tiene aún algún lugar en el mundo de hoy? O, puesto de otra forma, ¿es posible que otro concepto de Historia pueda sustituir al concepto moderno, que no se encuentra más - y no puede ya estarlo- en sintonía con el mundo que vio nacer el nuevo siglo? La Memoria, lo hemos visto, ocupa el primer lugar; en Europa, pero también más allá, se puso en marcha y cobró forma propia una cultura memorial, que se pone de manifiesto en los múltiples memoriales y en las múltiples conmemoraciones, grandes y pequeñas. Por una parte, la historia, la de los historiadores, se puso al servicio de esta Memoria, muy historiadora ella, de hecho, en su trayectoria, pues ha devenido investigadora, preocupada por archivos y por huellas de toda clase. Se trata de memorias voluntarias, más a reconocer que a encontrar, de memorias que no se tiene, que no pudieron tenerse (porque una cierta transmisión no ha podido realizarse), de una falta y de una ausencia que se busca llenar. De las memorias a hacer reconocer en el espacio público como un derecho: un derecho a la Memoria.

Por otra parte, para intentar ajustarse mejor a la realidad de un mundo después de las colonias y de la división dispuesta en Yalta, los historiadores propusieron unas respuestas, casi técnicas, que se denominaron: historia conectada, historia compartida, historia cruzada y, finalmente, historia global, con el objetivo de sustraerse así del régimen moderno de historicidad y de su teleología. Una cosa es segura, si un nuevo concepto de historia (quizá, justamente, sin H mayúscula) debía de surgir, no sería ya manufacturado en los talleres de Europa. De este modo, el tiempo de la Historia en singular o con $\mathrm{H}$ mayúscula no habría sido más que un momento, un momento en la vida de Clío. Antes hubo otras historias, y luego... ¿Estamos quizás en camino de recuperar las formas renovadas de aquellas historias en plural? 


\section{Referencias bibliográficas}

ARASSE, DANIEL (2001): Anselm Kiefer, París, Editions du Regard.

KOSELLECK, REINHART (2000): «Gibt es eine BeschleCHAKRABARTY, DIPESH (2009): Provincialiser l'Europe, La pensée postcoloniale et la différence historique, París.

unigung der Geschichte?», en: Zeitschichten, Francfort del Main, Suhrkamp Verlag.

KOSELLECK, REINHART (2016): Le Futur passé, París, Editions de l'École des Hautes Études en SciCHATEAUBRIAND, FRANÇOIS-RENÉ DE (2003/2004): ences Sociales.

Mémoires d'outre-tombe, t. I, édition critique de Jean-Claude Berchet, París, Le Livre de Poche/ Classiques Garnier.

COPANS, JEAN Y JAMIN, JEAN (1994): Aux origines de l'anthropologie française. Les mémoires de la société des observateurs de l'homme en I'an VIII, París, Jean-Michel Place.

LAROUSSE, PIERRE (1866/1877): Grand Dictionnaire Universel du XIXe siècle, vol. 12, París, Administration du Grand Dictionnaire Universel.

LÉVI-STRAUSS, CLAUDE (1958): Anthropologie structurale, París, Plon.

MORGAN, LEWIS (1971): La société archaïque, trad. française, París, Anthropos.

GUIZOT, FRANÇOIS (1985): Histoire de la civilisation en Europe, París, Hachette.

RENAN, ERNEST (1947): "Lettre à Marcellin Berthelot», en: CEuvres complètes, t. I, París, CalHARTOG, FRANÇOIS (2013): Croire en l'histoire, Paris, Flammarion. man-Lévy.

ROUSSEAU, JEAN-JACQUES (1964): Discours sur HARTOG, FRANÇOIS (2012): Régimes d'historicité, Présentisme et Expériences du temps, París, Seuil.

l'origine de l'inégalité, en: CEuvres complètes, t. III, París, Gallimard.

STOCKING JR, GEORGE W. (1987): Victorian Anthropo/INSEL, AHMET Y KAWAKIBI, SALAM (2016): «Des sociétés brutalisées: Entretien avec Ahmet Insel et Salam Kawakibi», Esprit, no 5 (mayo), pp. 60-75. ogy, Londres, Free Press.

TOCQUEVILLE, ALEXIS DE (1981): De la démocratie en Amérique, t. II, París, Garnier-Flammarion. 